\title{
DIVERSITY OF ARBUSCULAR MYCORRHIZAL FUNGI IN HORTICULTURAL PRODUCTION SYSTEMS OF SOUTHERN CHILE
}

\author{
C. Castillo ${ }^{1,3}$, R. Rubio ${ }^{2,3}$, F. Borie ${ }^{2,3}$, and E. Sieverding ${ }^{4}$ \\ ${ }^{1}$ Universidad Católica de Temuco, Facultad de Recursos Naturales, Escuela de Agronomía, \\ Casilla 15-D, Temuco, Chile. ${ }^{2}$ Universidad de La Frontera, Departamento de Ciencias Químicas y \\ Recursos Naturales, Temuco, Chile. ${ }^{3}$ Scientifical and Technological Bioresource Nucleus \\ (BIOREN), Universidad de La Frontera, Casilla 54-D, Temuco, Chile. ${ }^{4}$ University Hohenheim, \\ Institute of Plant Production and Agroecology in the Tropics and Subtropics, Garbenstr. 13, \\ 70599 Stuttgart, Germany. *Corresponding author: ccastill@uct.cl
}

\begin{abstract}
The diversity of arbuscular mycorrhizal (AM) fungi in six Capsicum annuum or Lycopersicum esculentum L. horticultural production systems of small farmers, and of two wheat agrosystems was comparatively investigated in Southern Chile (La Araucanía). Soils in this region are mostly originated by volcanic ashes which are characterized by high organic matter content and high P-fixing capacity. Arbuscular mycorrhizal fungal symbioses are playing a key role for P uptake by horticultural crops grown there. The objective of this study was to determine AM fungal communities in cropping systems and to identify soil factors affecting their frequency and diversity. Of the totally 32 AM fungal species identified, 5 to 21 AM fungi species were found in horticultural locations and 8 to 11 AM fungi species in conventional tillage (CT) and no-tillage (NT) agroecosystems. No relationships on AM fungal diversity with soil factors were found. In wheat based agrosystems fungal diversity was somewhat lower under CT than NT whereas no such relationships between diversity and intensity of land use could be generated from horticultural systems. It is concluded that it will be advisable for farmers to inoculate their horticultural crops with selected mycorrhizal inoculants during the nursery stage, as it cannot be predicted from the soil conditions whether the native AM fungal community is sufficient to sustain a stable horticultural production in the region.
\end{abstract}

Keywords: Glomeromycetes, pepper, lettuce, agro-ecosystems.

\section{INTRODUCTION}

Soil microbiota plays a fundamental role for the productivity and stability of horticultural and agroecosystems in the volcanic soils of Southern Chile (Castillo et al., 2006b; 2009). Within this microbiota arbuscular mycorrhizal (AM) fungi stand out because they are so important for the phosphate $(\mathrm{P})$ nutrition of plants in the acidic Andisols (Borie et al., 2010). They establish a mutualistic symbiosis with most of terrestrial plants and this type of mycorrhiza is by far the most important worldwide. It is said that it occurs with more than $60 \%$ of the species of the plant kingdom (Trappe, 1987). Fungal species involved in the formation of AM belong to the Glomeromycota (Schüssler et al., 2001). 
Among the factors influencing the AM fungal community dynamics and associations with plants, agricultural practices may be considered to be the most important. Tillage, crop rotation sequences, and crop management systems have been reported as critical factors affecting the development, activity and diversity of AM fungi (Oehl et al., 2003; 2005). Mycorrhizal propagules can survive in the soil as spores which appear to be long-term structures of different ages, states of dormancy and germination periods and they constitute an inoculum source persisting for many years (Smith and Read, 2009). Hence, these fungal propagules represent the native mycorrhizal inoculum potential for locally grown crops. The fungal species naturally present in agrosystems may be decisive for the productivity of crops in the Pdeficient soils of Southern Chile. The main purpose of this study was to investigate the occurrence of AM fungi species in some horticultural ecosystems in some soils of Southern Chile, and to determine whether there is any relation between their occurrence and soil factors. As for comparison, no till and conventional wheat agrosystems were included in the study.

\section{MATERIALS AND METHODS}

Two agroecosystems were selected for the study in the Araucanía Region of Chile: horticultural systems habitually cropped by local farmers with vegetables such as pepper and tomato, and a wheat based cropping system. Soil samples were taken from six districts where vegetables are

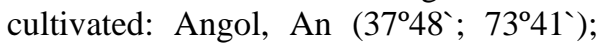
Lumaco, Lu (3840`; $\left.73^{\circ} 58^{`}\right)$; Purén, $\mathrm{Pu}$ (3809`; 7300`); Los Sauces, Sau (38¹5`; $\left.72^{\circ} 50^{`}\right)$; Vilcún, Vil (384ำ72¹4`); Lobería, Lo (38³9`; $\left.73^{\circ} 29^{\circ}\right)$, and from wheat cultivated under no tillage (NT) and conventional tillage (CT) at Pumalal (38 $\left.40^{\circ} ; 72^{\circ} 31^{\prime}\right)$.

In Angol, Lumaco, Purén, and Los Sauces the soils were cultivated with chili pepper (Capsicum annuum L.) locally named "Cacho de Cabra", for many decades. In Vilcún soil, tomato was cultivated and at Lobería the soil was under fallow, after a previous vegetable cropping (Table 1). Four soil samples from the $0-10 \mathrm{~cm}$ horizon were taken from $10 \mathrm{~m}^{2}$ plots from within the planting rows and between the rows. There were 4 replicated plots per location. Soil samples from each plot were bulked to give four replicates per ecosystem; soil samples were brought to the lab and stored in a freezer until analyses for separation of spores and the identification of AM fungi species, and for soil analyses.

In each ecosystem the following soil chemical parameters were determined: a) soil $\mathrm{pH}$ which was measured by glass electrode in a 1:2.5 soil: water suspension; b) available phosphorus which was determined after extraction with a solution of $0.5 \mathrm{M} \mathrm{NaHCO}_{3}$ at $\mathrm{pH}$ 8.5 (Olsen and Sommers, 1982; and c) soil organic matter (SOM), was measured according to Walkley and Black (1934). Such soil characteristics appear in Table 1.

Spores of AM fungi were extracted and separated from the soil using the wetsieving and decanting procedure described by Sieverding (1991). Spores were isolated under a stereomicroscope and fixed in polyvinyl alcohol-lactic acidglycerol (PVLG), and a mixture of PVLG and Melzer`s reagent (Brundrett et al., 1996) to obtain permanent specimen. For the taxonomic classification main morphological spore characteristics such as colour, size, type and number of spore walls, and the morphology of the subtending hypha at the point of spore attachment were observed under a high- 
Table 1. Soil chemical characteristics in the horticultural and agroecosystems of Southern Chile investigated.

\begin{tabular}{lclccc}
\hline Community & $\begin{array}{c}\text { Time of } \\
\text { sampling }\end{array}$ & \multicolumn{1}{c}{ Vegetation at sampling } & pH & $\begin{array}{c}\text { Olsen-P } \\
\left(\mathbf{m g ~} \mathbf{~ k g}^{-1} \mathbf{)}\right.\end{array}$ & $\begin{array}{c}\text { SOM } \\
\mathbf{( \% )}\end{array}$ \\
\hline Angol & April 2007 & Chili pepper harvest, mature fruits & 7.3 & 106 & 7.0 \\
Los Sauces & April 2007 & Tomato harvest, mature fruits & 5.5 & 10 & 6.0 \\
Lumaco & April 2007 & Chili pepper harvest, mature fruits & 5.9 & 38 & 6.0 \\
Purén & October 2006 & Fallow after harvest of chili pepper & 5.9 & 48 & 5.0 \\
Lobería & December 2007 & Fallow; vegetable crop in the & 6.1 & 4.0 & 1.8 \\
Vilcún & December 2007 & Host tomato, trial 4 months old & 6.1 & 5.5 & 8.2 \\
Pumalal CT & April 2003 & Fallow after wheat harvest & 5.8 & 22 & 8.2 \\
Pumalal NT & April 2003 & Fallow after wheat harvest & 5.8 & 18 & 8.2 \\
\hline
\end{tabular}

power light microscope at 100x and 400x magnification. Species identification was carried out using the keys and instructions given by Schenck and Pérez (1990) and INVAM (International Culture Collection of Arbuscular and Vesicular-Arbuscular Endomycorrhizal Fungi, see internet homepage: www.invam.caf.wvu.edu). All isolated specimen were deposited at the Laboratory of Plant Nutrition of the Universidad de La Frontera, Temuco, Chile.

\section{RESULTS AND DISCUSSION}

In total, 32 species of Glomeromycota were found in the six horticultural and the two wheat crop systems studied (Table 2).

Of the known species, 17 of them were previously not described (Castillo et al., 2006a) from Southern Chile: Acaulospora alpina, Ac. laevis, Ac. longula, Ac. paulina, Ac. undulata, Glomus aggregatum, Gl. claroideum, Gl. clavisporum, Gl. fasciculatum, Gl. geosporum, Gl. monosporum, Gl. mosseae, Gl. pallidum, Gl. vesiculiferum, Gl. versiforme, Pacispora dominikii, and
Paraglomus occultum. The number of species was highly variable among the horticultural production sites ranging from 5 species in Purén to 21 species in Vilcún, and was less variable in wheat production systems with 8 species under CT to 11 species under NT.

Only 6 of the 32 AM fungal species were found at $50 \%$ or more of the districts, so that their geographic distribution was somewhat higher than the other species: Archaeospora trappei, Gl. coronatum, Gl. diaphanum, Gl. etunicatum, Gl. intraradices, and Gl. versiforme. This may indicate that these species are fit to survive and form spores under very diverse conditions. Therefore, these 6 fungal species can be considered ecological generalists (Castillo et al., 2006a). In this sense, Gl. etunicatum is known as a generalist from European studies (Oehl et al., 2004), and from evergreen forests, deciduous forests and grassland ecosystems of Southern Chile (Castillo et al., 2006a). On the other hand, Gl. versiforme only is a generalist species in horticultural ecosystem; whilst some other species like Gl. invermaium, and Scutellospora calospora, were only observed in the wheat production system. 
Table 2. Genera and species of the Glomeromycota found in the horticultural systems in Angol (An), Lumaco (Lu), Purén (Pu), Los Sauces (Sau), Vilcún (Vil), Lobería (LO), and agroecosystems at Pumalal under no-tillage (NT) and conventional tillage (CT).

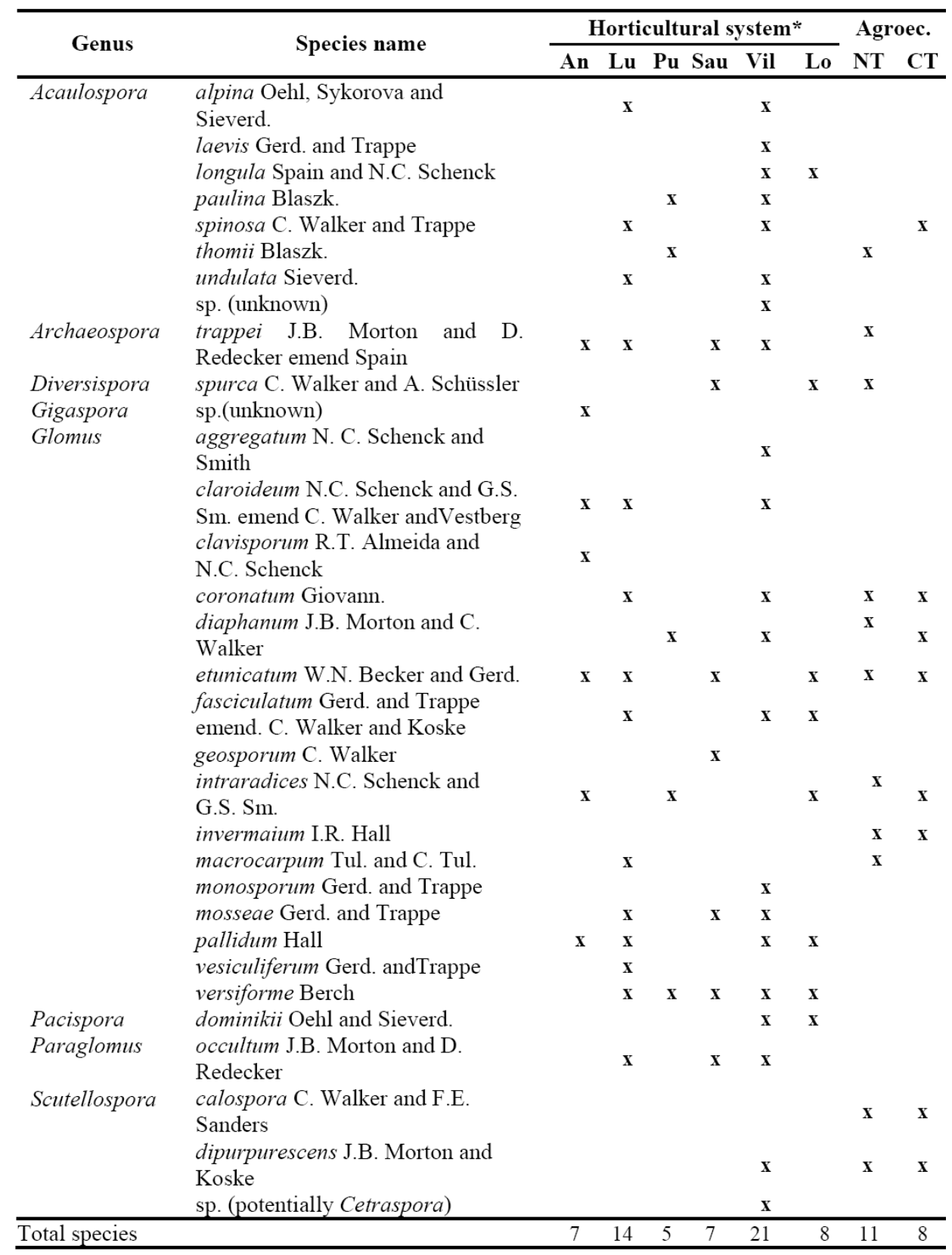

* $\mathrm{x}$ indicates presence of arbuscular mycorrhizal fungal species 
Some species appear to be not common, such as five species isolated at Vilcún, like $A$. laevis, an unknown Acaulospora sp., Gl. aggregatum, Gl. monosporum, and a Scutellospora sp.; two species at Angol: a Gigaspora sp. and Gl. clavisporum; one in Los Sauces: Gl. geosporum ; whilst at Lumaco, a species similar to Gl. vesiculiferum was identified. All these AM fungal species were only found once. Four AM fungal species were identified only at genera level (Table 2) originating from the districts of Vilcún and Angol.

In horticultural system, Lumaco and Vilcún soils presented relatively high diversity of AM fungi, and in the wheat cropping systems, higher species numbers were found under NT than CT. The function and importance of each of the different AM fungal species in each ecosystem still remains unknown.

In both ecosystems, the horticultural and the wheat cropping systems, Glomus spp. represented each about $60 \%$ of all AM fungal species found clearly the majority of the AMF community (Figure 1). It is not surprising that most of AM fungi spores owned to the Glomus genus because this is the prevailing genus in agricultural soils among the AM species described so far (Jansa et al., 2003), and also in Chile, in a wheat-oat crop rotation with the application of different tillage systems in an Ultisol most species belonged to the genus Glomus (Castillo et al., 2006b). Similar results were obtained from European grasslands (Oehl et al., 2004).

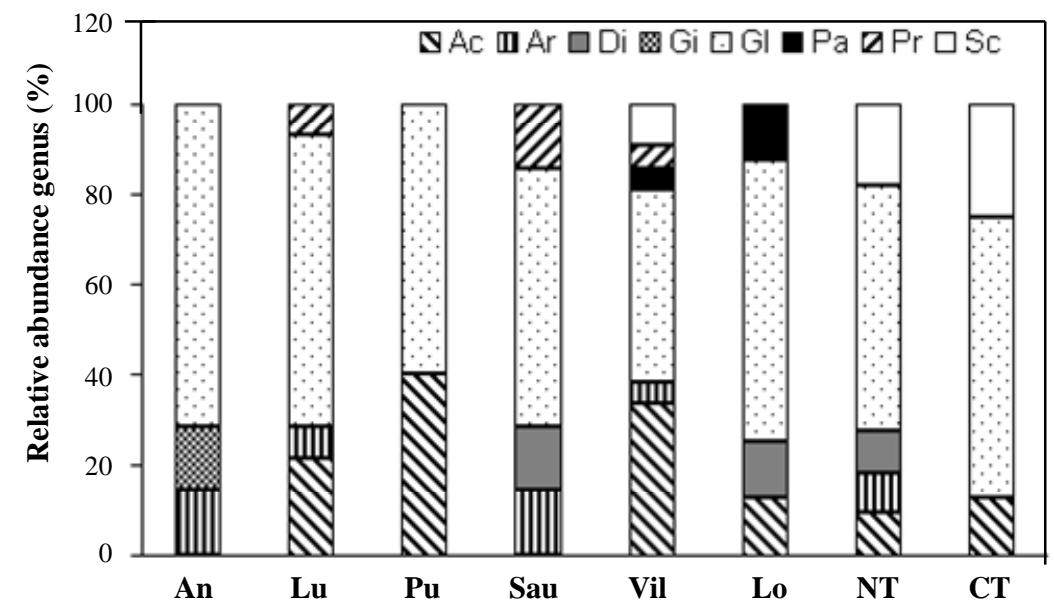

Figure 1. Relative abundance of fungal species for each genus (number of all fungal species identified at each site set to $100 \%$ ) in agrosystems investigated of Southern Chile. Districts are: An: Angol; Lu: Lumaco; Pu: Purén; Sau: Los Sauces; Vil: Vilcún; Lo: Lobería; NT: notillage; CT: conventional tillage. Fungal genera found were: Ac: Acaulospora; Ar: Archaeospora; Di: Diversispora; Gi: Gigaspora; Gl: Glomus; Pa: Pacispora; Pr: Paraglomus; Sc: Scutellospora.

No correlation was found between the species richness, or occurrence of specific fungal species and the soil characteristics like organic matter content, $\mathrm{P}$ content or soil $\mathrm{pH}$. Hence, from these parameters it is not predictable which fungal species 
might occur at a specific site. Horticultural systems in the region are often fertilized with high amounts or in contrast with reduced amounts of fertilizers depending on the economic situation of the small farmers. Very high available P contents of soils (e.g. Angol) may be an indicator for high organic or chemical fertilizer inputs. It is not clear from the current investigation whether such high inputs have a dramatic negative effect on the appearance of different fungal species as for example was demonstrated from European agricultural monocropping systems (Oehl et al., 2003). Deeper studies could show such effects, but at this time we conclude that the bio-diversity in small farm horticultural systems in the Araucanía region is highly variable and not predictable from soil characteristics. This indeed may call for active management of mycorrhiza in horticultural systems by inoculation with selected effective mycorrhizal inoculants. Because the farmer will not know what kind of AM fungi species in which concentration he has in his field, he will produce a horticultural crop with less risk when inoculating his crop with selected mycorrhizal fungi at the nursery stage. Mycorrhizal seedlings are then transplanted to the field which will likely give a more secure production. Unfortunately, such mycorrhizal inocula are not yet available in the region but recent research has shown that inoculum production at large scale is possible in Chile (Castillo et al., 2009). It is now up to commercial companies to make such inocula available.

\section{CONCLUSIONS}

The diversity of AM fungal species is highly variable in chilli pepper and tomato based horticultural production systems of small farmers in the Araucanía region of Chile. There is no relationship between the most common soil parameters with such diversity, and the occurrence or absence of AM fungi species is likely to depend on the divers agronomic historic inputs, that farmer apply to horticultural crops. Thus, because most of the horticultural crops depend obligatorily for growth on mycorrhizae, in the soils of the region, it is advisable to inoculate the horticultural crops with selected highly effective mycorrhizal inoculants at the nursery stage especially in organic agriculture. This will likely give farmers a more secure and sustainable production than to depend in crop production on unknown natural AM fungi communities.

\section{ACKNOWLEDGEMENTS}

This study was partially financed by FONDECYT Project 1070283, from Comisión Nacional de Investigación Científica y Tecnológica, CONICYT, Chile.

\section{REFERENCES}

Borie, F., Rubio, R., Morales, A., Cornejo, P. 2010. Arbuscular mycorrhizae in agricultural and forest ecosystems in Chile. J. Soil Sci. Plant Nutr. 10, 204-223.

Brundrett, M., Bougher, N., Dell, B., Grove, T., Malajczuk, N. 1996. Working with Mycorrhizas in Forestry and Agriculture. Australian Centre for International Agricultural Research, ACIAR, Monograph 32.

Castillo, C.G., Borie, F., Godoy, R., Rubio, R., Sieverding, E. 2006a. Diversity of mycorrhizal plant species and arbuscular mycorrhizal fungi in evergreen forest, deciduous forest and grassland ecosystems of Southern Chile. J. Appl. Bot. Food Qual. 80, 40-47.

Castillo, C.G., Rubio, R., Rouanet, J.L., Borie,

F. 2006b. Early effects of tillage and crop 
rotation on arbuscular mycorrhizal fungal propagules in an Ultisol. Biol. Fertil. Soils 43, 83-92.

Castillo, C.G., Sotomayor, L., Ortiz, C., Leonelli, G., Borie, F., Rubio, R. 2009. Effect of arbuscular mycorrhizal fungi on an ecological crop of chili peppers (Capsicum annuum L.). Chilean J. Agric. Res. 69, 79-87.

Jansa, J., Mozafar, A., Khun, G., Anken, T. Ruh, R., Sanders, I.R., Frossard, E. 2003. Soil tillage affects the community structure of mycorrhizal fungi in maize roots. Ecol. Appl. 13, 1164-1176.

Oehl, F., Sieverding, E., Ineichen, K., Mäder, P., Boller, T., Wiemken, A. 2003. Impact of land use intensity on the species diversity of arbuscular mycorrhizal fungi in agroecosystems of Central Europe. Appl. Environ. Microbiol. 69, 2816-2824.

Oehl, F., Sieverding, E., Mäder, P., Dubois, D., Ineichen, K., Boller, T., Wiemken, A. 2004. Impact of long-term conventional and organic farming on the diversity of arbuscular mycorrhizal fungi. Oecologia 138, 574-583.

Oehl, F., Sieverding, E., Ineichen, K., Ris, E.A., Boller, T., Wiemken, A. 2005 Community structure of arbuscular mycorrhizal fungi at different soil depths in extensively and intensively managed agroecosystems. New Phytol. 265, 273-283.
Olsen, S.R., Sommers, L.E. 1982. Phosphorus. In: Page, A.L., Miller, R.H., Keeney, D.R. (Eds.). Methods of Soil Analysis. Part 2. Chemical and Microbiological Properties. SSSA, Madison, pp. 403-430.

Schenck, N.C., Pérez, Y. 1990. Manual for the Identification of VA Mycorrhizal Fungi. $3^{\mathrm{a}}$ edition, Synergistic, Gainesville, Florida, U.S.A. $241 \mathrm{p}$.

Schüssler, A., Schwarzott, D., Walker, C. 2001. A new fungal phylum, the Glomeromycota: phylogeny and evolution. Mycol. Res. 105, 14131421.

Sieverding, E. 1991. Vesicular-arbuscular Mycorrhiza Management in Tropical Agrosystems. GTZ, Eschborn, Germany. 371 p.

Smith, S.E., Read, D.J. 2009. Mycorrhizal Symbiosis. Academic Press, London. 605 p.

Trappe, J.M. 1987. Phylogenetic and ecologic aspects of mycotrophy in the angiosperms from an evolutionary standpoint. In: Safir, G.R. (Eds.). Ecophysiology of VA Mycorrhizal Plants. CRC Press, Boca Raton, Florida. pp. 5-25.

Walkley, A., Black, I.A. 1934. An examination of the Degtjareff method for determining soil organic matter and a proposed modification of the chromic acid titration method. Soil Sci. 37, 29-38. 